\title{
Influence of niobium and yttrium on plastic deformation energy and plasticity of Ti-based amorphous alloys
}

\author{
*Sheng-feng Shan', Hao Wang' ${ }^{2}$ Bing Zhang ${ }^{3}$, Yuan-zhi Jia ${ }^{3}$, Ming-zhen Ma ${ }^{3}$ \\ 1. Department of Physics, Jining University, Qufu 273155, China \\ 2. Ningbo Institute of Materials Technology and Engineering, Chinese Academy of Sciences, Ningbo 315201, China \\ 3. State Key Laboratory of Metastable Materials Science and Technology, Yanshan University, Qinhuangdao 066004, China
}

\begin{abstract}
Many amorphous alloys have been developed to date, but the low plasticity has limited their application. To achieve an amorphous alloy with high plasticity, a series of $\left(\mathrm{Ti}_{40} \mathrm{Zr}_{25} \mathrm{Cu}_{9} \mathrm{Ni}_{8} \mathrm{Be}_{18}\right)_{100-x} \mathrm{TM}_{x}(x=0$, 1, 2, 3, 4 at.\%, $\mathrm{TM}=\mathrm{Nb}, \mathrm{Y}$ ) alloys were designed to study the influence of $\mathrm{Nb}$ and $\mathrm{Y}$ addition on the plasticity. The amorphous samples were prepared using the vacuum melting and copper mold casting process. The microstructures, glass forming ability and mechanical properties of the alloys were investigated by X-ray diffractometry (XRD), scanning electron microscopy (SEM), high-resolution transmission electron microscopy (HRTEM), depth-sensitive nanoindentation, and uniaxial compressive test. The plasticity of different bulk amorphous alloys was investigated by measuring the plastic deformation energy (PDE) during loading. The relationship between the PDE value and plasticity in bulk amorphous alloys was explored. Results show that $\mathrm{Nb}$ addition decreases the PDE value and promotes the generation of multiple shear bands, which significantly increases the fracture strength and plasticity, while the addition of $Y$ element reduces the fracture strength and plastic strain of the alloy.
\end{abstract}

Key words: copper mold casting; bulk amorphous alloy; plastic deformation energy; plasticity

CLC numbers: TG146.23 Document code: A Article ID: 1672-6421(2021)01-060-08

\section{Introduction}

Bulk amorphous alloys have excellent properties, such as high strength and high hardness, that make the alloys very good structural material candidates ${ }^{[1-4]}$. Researchers have developed many multi-component bulk amorphous alloys, for example, Pd-, Zr-, Fe-, Co-, $\mathrm{Ni}$-, and Ti-based alloys ${ }^{[5-8]}$. However, the deformation characteristics of amorphous alloys result in very low room-temperature plasticity, limiting their application as structural materials ${ }^{[9]}$. Amorphous alloys with a greater Poisson's ratio are more likely to generate new shear bands during deformation, and thus the growth of cracks is impeded ${ }^{[10]}$. In recent years, many methods have been used to avoid brittle fracture due to local shear failure and improve the mechanical properties of bulk

\section{*Sheng-feng Shan}

Male, born in 1969, Ph.D., Associate Professor at Jining University. His current research interest mainly focuses on the manufacturing and characterization of Ti-based amorphous casting alloys.

E-mail: sdjnssf@163.com;

Received: 2020-10-09; Accepted: 2020-12-10 amorphous alloys. Researchers have proposed changing the crystallization mode of amorphous alloys by adding elements, such as $\mathrm{Ag}, \mathrm{Pd}, \mathrm{Au}, \mathrm{Pt}$, or $\mathrm{Y}^{[11,12]}$; precipitating quasicrystals or nanocrystals in an amorphous matrix through an annealing process; generating ductile phase dendrites in situ from the amorphous matrix by adding high melting-point elements, such as $\mathrm{Ta}$ and $\mathrm{Nb}$ in amorphous alloys ${ }^{[13-17]}$. The second phase in ductile phase dendrites interacts with the shear bands to limit the shear slip of the amorphous matrix on its maximum shear stress surface, and improves the plastic deformation ability of the bulk amorphous alloys ${ }^{[18]}$. The generation and expansion of shear bands have a great influence on the plasticity of amorphous alloys and play an important role in the alloys' deformation and fracture process ${ }^{[19]}$. The nanoindentation of the depthsensing technology has been applied to measure the mechanical properties of materials ${ }^{[20-27]}$ and calculate the plastic deformation energy (PDE) ${ }^{[28]}$.

The multi-component alloy, $\mathrm{Ti}_{40} \mathrm{Zr}_{25} \mathrm{Cu}_{9} \mathrm{Ni}_{8} \mathrm{Be}_{18}$, has a strong amorphous forming ability; however, its plastic deformation ability should be improved. The addition of an element is a well-known effective means to improve 
the plasticity of amorphous alloys. In this study, the amorphous alloys containing $\mathrm{Nb}$ and $\mathrm{Y}$ elements, $\left(\mathrm{Ti}_{40} \mathrm{Zr}_{25} \mathrm{Cu}_{9} \mathrm{Ni}_{8} \mathrm{Be}_{18}\right)_{100-x} \mathrm{TM}_{x}$ $(x=0,1,2,3,4$ at.\%, $\mathrm{TM}=\mathrm{Nb}, \mathrm{Y})$, were designed and prepared. The microstructure, glass forming ability and mechanical properties of the alloys were investigated. The relationship among the PDE by the addition of $\mathrm{Nb}$ or $\mathrm{Y}$, shear bands formation, and plastic deformation of amorphous alloys was studied.

\section{Materials and methods}

The amorphous alloys $\left(\mathrm{Ti}_{40} \mathrm{Zr}_{25} \mathrm{Cu}_{9} \mathrm{Ni}_{8} \mathrm{Be}_{18}\right)_{100-x} \mathrm{TM}_{x}(x=0,1$, 2, 3, 4 at. $\%, \mathrm{TM}=\mathrm{Nb}$ or $\mathrm{Y}$ ) were prepared using a mixture of Ti (99.99\%), Zr (99.9\%), Be (99.9\%), Ni (99.99\%), Cu (99.999\%), $\mathrm{Nb}(99.99 \%)$, and Y (99.9\%).

The oxide film on the surface of the raw materials was removed with a metal brush and cleaned with an ultrasonic cleaner using anhydrous ethanol and acetone for $10 \mathrm{~min}$. An electronic balance with an accuracy of $0.0001 \mathrm{~g}$ was used to mix the ingredients according to the atomic percentage and composition of the alloys. The arc melting chamber was cleaned using absolute ethanol, and the prepared raw materials were placed inside the copper crucible.

Next, the vacuum mechanical pump was started for prevacuuming (vacuuming the melting and casting chambers together). When the pressure in the vacuum gauge (which showed the vacuum degree of the melting and casting chambers) reached $10^{-1} \mathrm{~Pa}$, the valve connected to the mechanical pump was closed. Then, the valve connected to the molecular pump was opened and subsequently closed. The gate between the melting and casting chambers was sealed when the vacuum degree reached $2.0 \times 10^{-3} \mathrm{~Pa}$ (the maximum vacuum degree of the equipment was $10^{-4} \mathrm{~Pa}$ ). An arc melting furnace was used to melt a mixture of high-purity elements that was deposited on a water-cooled copper core by charging argon (99.9999\%). All ingots were remelted at least three times to ensure uniform composition. When the ingots were completely melted, the suction casting valve was opened, and the suction casting chamber was vacuumed; this resulted in a pressure difference between the melting and suction casting chambers. The metal with the lowest viscosity was sucked into the copper mold and cooled rapidly to form a bulk amorphous alloy.

An X-ray diffractometer (D/max-2500/pc, Ricoh, Japan) was used to conduct diffraction analysis of the cross section of the sample. The electron diffraction pattern of the sample was observed using a high-resolution transmission electron microscope (HRTEM, JEM-2010). The mechanical properties were measured using an MTS810 test machine. Uniaxial compression tests were conducted on the specimens with a height of $6 \mathrm{~mm}$ and a diameter of $3 \mathrm{~mm}$ (aspect ratio of 2:1) at ambient temperature and a strain rate of $2 \times 10^{-4} \mathrm{~s}^{-1}$. The fracture morphology was observed using a scanning electron microscope (SEM, kyky-2800).

An MTS nanoindentation system (Nano Indenter XP MTS Ltd., American) equipped with a spherical indenter (with a radius of $10.8 \mu \mathrm{m}$ ) was used to determine the mechanical characteristics of the sample. The loading rate was $1 \mathrm{mN} \cdot \mathrm{s}^{-1}$ at room temperature, and the sample surface was carefully polished before the test. Each sample was tested at least 20 times with a spacing of approximately $20 \mu \mathrm{m}$ between adjacent indentations. The maximum load was $700 \mathrm{mN}$, and the loading depth limit was set to $2,000 \mathrm{~nm}$.

\section{Results}

\subsection{Glass forming ability of alloy}

Figure 1 presents the $\mathrm{X}$-ray diffraction (XRD) patterns of $\mathrm{Ti}_{40} \mathrm{Zr}_{25} \mathrm{Cu}_{9} \mathrm{Ni}_{8} \mathrm{Be}_{18},\left(\mathrm{Ti}_{40} \mathrm{Zr}_{25} \mathrm{Cu}_{9} \mathrm{Ni}_{8} \mathrm{Be}_{18}\right)_{100-x} \mathrm{Y}_{x}(x=1,2$ at.\%) and $\left.\mathrm{Ti}_{40} \mathrm{Zr}_{25} \mathrm{Cu}_{9} \mathrm{Ni}_{8} \mathrm{Be}_{18}\right)_{100-x} \mathrm{Nb}_{x}(x=1,2,3,4$ at.\%). No obvious sharp diffraction peak is found in the diffraction spectra of $\mathrm{Ti}_{40} \mathrm{Zr}_{25} \mathrm{Cu}_{9} \mathrm{Ni}_{8} \mathrm{Be}_{18},\left(\mathrm{Ti}_{40} \mathrm{Zr}_{25} \mathrm{Cu}_{9} \mathrm{Ni}_{8} \mathrm{Be}_{18}\right)_{100-x} \mathrm{Nb}_{x}(x=1,2,3$, 4 at.\%) and $\left(\mathrm{Ti}_{40} \mathrm{Zr}_{25} \mathrm{Cu}_{9} \mathrm{Ni}_{8} \mathrm{Be}_{18}\right)_{99} \mathrm{Y}_{1}$ alloys, indicating the typical amorphous nature of the samples. In contrast, the XRD patterns of the $\left(\mathrm{Ti}_{40} \mathrm{Zr}_{25} \mathrm{Cu}_{9} \mathrm{Ni}_{8} \mathrm{Be}_{18}\right)_{98} \mathrm{Y}_{2}$ alloy shows that the crystallization peak is superimposed on the broad diffused scattering peak, and a polycrystalline is observed, indicating that the crystallization occurred in the alloy. To further study the uniformity and structure of amorphous alloys, high-resolution TEM micrographs and selected-area electron diffraction patterns of $\mathrm{Ti}_{40} \mathrm{Zr}_{25} \mathrm{Cu}_{9} \mathrm{Ni}_{8} \mathrm{Be}_{18},\left(\mathrm{Ti}_{40} \mathrm{Zr}_{25} \mathrm{Cu}_{9} \mathrm{Ni}_{8} \mathrm{Be}_{18}\right)_{99} \mathrm{Y}_{1}$, and $\left(\mathrm{Ti}_{40} \mathrm{Zr}_{25} \mathrm{Cu}_{9} \mathrm{Ni}_{8} \mathrm{Be}_{18}\right)_{97} \mathrm{Nb}_{3}$ and $\left(\mathrm{Ti}_{40} \mathrm{Zr}_{25} \mathrm{Cu}_{9} \mathrm{Ni}_{8} \mathrm{Be}_{18}\right)_{98} \mathrm{Y}_{2}$ were analyzed, as shown in Fig. 2. The microstructure is uniform, composing of a single phase without precipitation of the crystal phase. The diffraction of the selected region is a typical amorphous diffraction ring in $\mathrm{Ti}_{40} \mathrm{Zr}_{25} \mathrm{Cu}_{9} \mathrm{Ni}_{8} \mathrm{Be}_{18}$, $\left(\mathrm{Ti}_{40} \mathrm{Zr}_{25} \mathrm{Cu}_{9} \mathrm{Ni}_{8} \mathrm{Be}_{18}\right)_{99} \mathrm{Y}_{1}$, and $\left(\mathrm{Ti}_{40} \mathrm{Zr}_{25} \mathrm{Cu}_{9} \mathrm{Ni}_{8} \mathrm{Be}_{18}\right)_{97} \mathrm{Nb}_{3}$. However, the HRTEM and diffraction patterns of the $\left(\mathrm{Ti}_{40} \mathrm{Zr}_{25} \mathrm{Cu}_{9} \mathrm{Ni}_{8} \mathrm{Be}_{18}\right)_{98} \mathrm{Y}_{2}$ alloy confirm the crystallization in Fig. 2(d). As the content of the Y element increases, the crystallization becomes more severe (not shown here).

\subsection{Macro-compression performance of amorphous alloys}

Figure 3 shows the compressive stress-strain curves of the as-

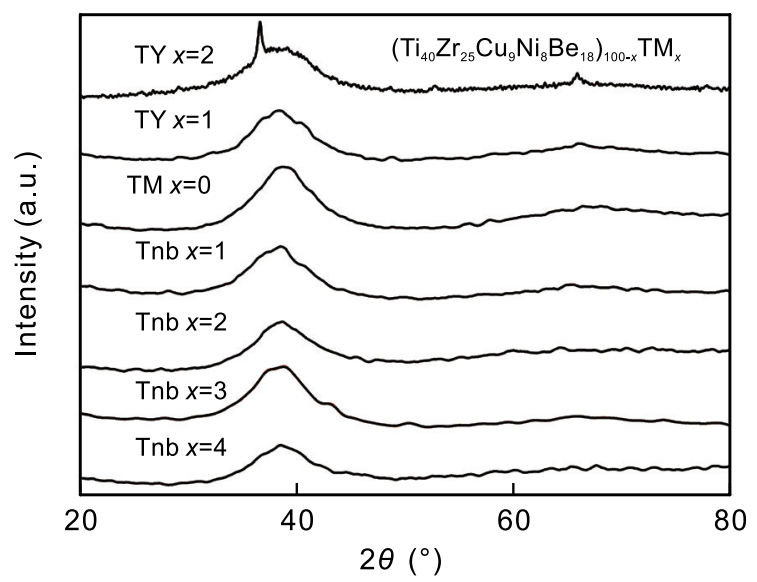

Fig. 1: X-ray diffraction patterns of as-cast alloys: $\left(\mathrm{Ti}_{40} \mathrm{Zr}_{25} \mathrm{Cu}_{9} \mathrm{Ni}_{8} \mathrm{Be}_{18}\right)_{100-x} \mathrm{TM}_{x}(x=$ 0, 1, 2 at.\%, TM $=\mathrm{Y})$ and $\left.\mathrm{Ti}_{40} \mathrm{Zr}_{25} \mathrm{Cu}_{9} \mathrm{Ni}_{8} \mathrm{Be}_{18}\right)_{100-x} \mathrm{TM}_{x}(x=$ 0, 1, 2, 3, 4 at.\%, $\mathrm{TM}=\mathbf{N b}$ ) 

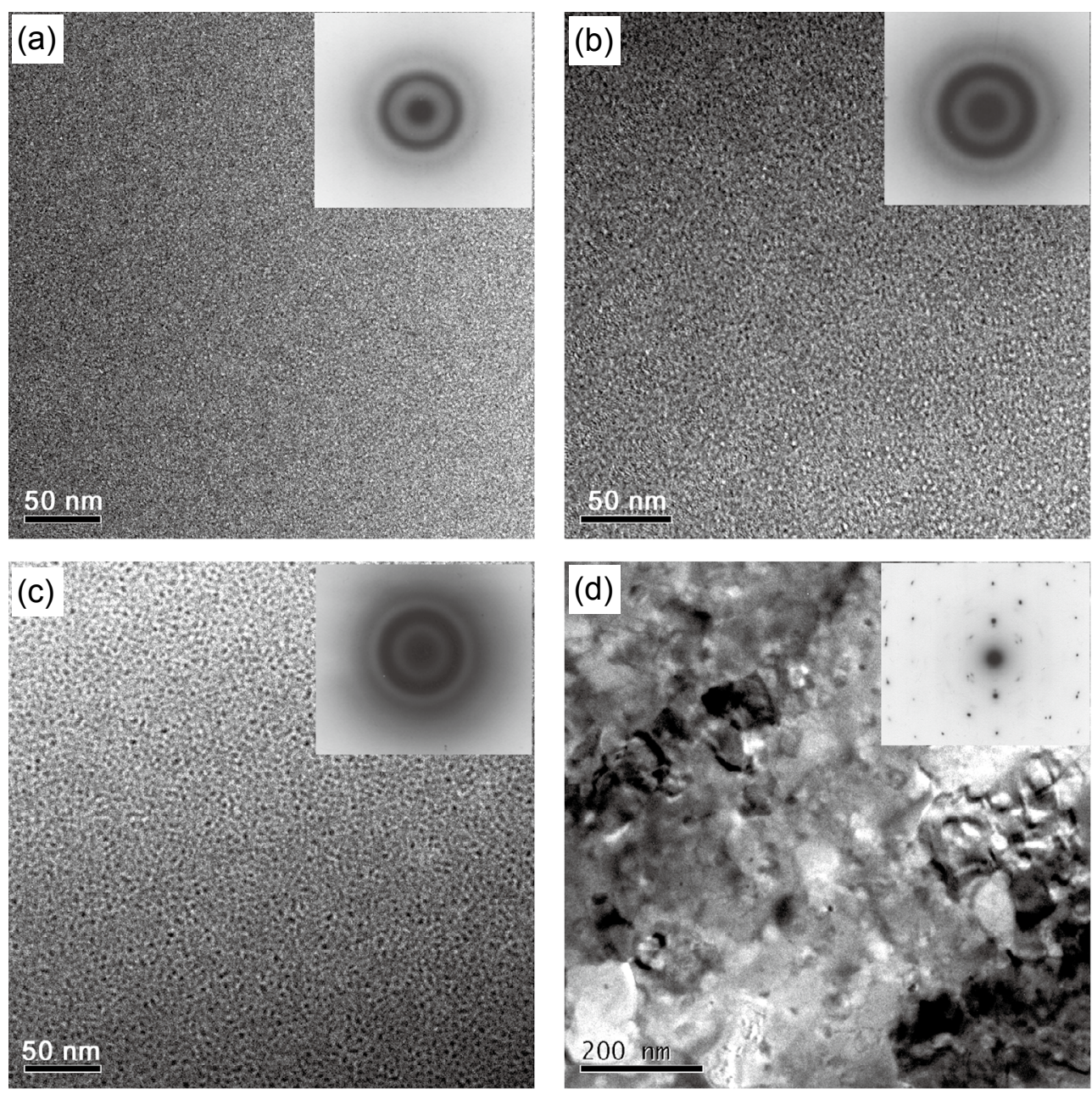

Fig. 2: High-resolution TEM micrographs and selected-area electron diffractions of the amorphous alloys:

(a) $\mathrm{Ti}_{40} \mathrm{Zr}_{25} \mathrm{Cu}_{9} \mathrm{Ni}_{8} \mathrm{Be}_{18}$; (b) $\left(\mathrm{Ti}_{40} \mathrm{Zr}_{25} \mathrm{Cu}_{9} \mathrm{Ni}_{8} \mathrm{Be}_{18}\right)_{99} \mathrm{Y}_{1}$; (c) $\left(\mathrm{Ti}_{40} \mathrm{Zr}_{25} \mathrm{Cu}_{9} \mathrm{Ni}_{8} \mathrm{Be}_{18}\right)_{97} \mathrm{Nb}_{3}$; and (d) $\left(\mathrm{Ti}_{40} \mathrm{Zr}_{25} \mathrm{Cu}_{9} \mathrm{Ni}_{8} \mathrm{Be}_{18}\right)_{98} \mathrm{Y}_{2}$

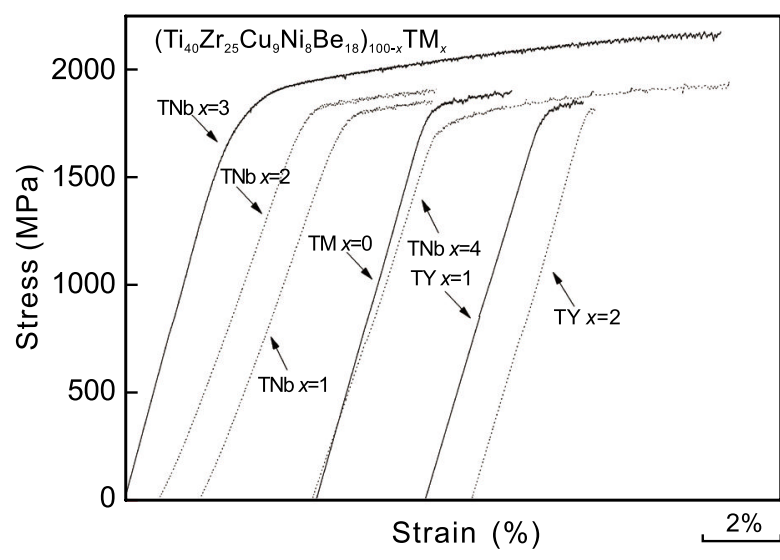

Fig. 3: Compressive stress-strain curves of as-cast $\left(\mathrm{Ti}_{40} \mathrm{Zr}_{25} \mathrm{Cu}_{9} \mathrm{Ni}_{8} \mathrm{Be}_{18}\right)_{100-x} \mathrm{TM}_{x}$ alloys, TM: no addition of $\mathrm{Nb}$ or $\mathrm{Y}$; $\mathrm{TNb}$ : addition of $\mathrm{Nb}$ with $\mathrm{X}=1,2,3,4$; TY: addition of $Y$ with $x=1,2$

cast alloys at room temperature with the addition of $\mathrm{Nb}$ or $\mathrm{Y}$ to $\mathrm{Ti}_{40} \mathrm{Zr}_{25} \mathrm{Cu}_{9} \mathrm{Ni}_{8} \mathrm{Be}_{18}$. The room temperature mechanical properties of different alloys were measured and summarized in Table 1. The stress-strain curve shows the compressive strength and plastic deformation of the $\mathrm{Ti}_{40} \mathrm{Zr}_{25} \mathrm{Cu}_{9} \mathrm{Ni}_{8} \mathrm{Be}_{18}$ amorphous alloy are $1,896 \mathrm{MPa}$ and $2.1 \%$, respectively. With the addition of $\mathrm{Nb}$, the fracture and plastic deformation of $\left(\mathrm{Ti}_{40} \mathrm{Zr}_{25} \mathrm{Cu}_{9} \mathrm{Ni}_{8} \mathrm{Be}_{18}\right)_{97} \mathrm{Nb}_{3}$ increase to 2,177 $\mathrm{MPa}$ and $13 \%$, respectively. However, the $\left(\mathrm{Ti}_{40} \mathrm{Zr}_{25} \mathrm{Cu}_{9} \mathrm{Ni}_{8} \mathrm{Be}_{18}\right)_{99} \mathrm{Y}_{1}$ amorphous alloy shows a compressive strength of $1,870 \mathrm{MPa}$ and plastic strain of only $1.1 \%$. For the $\left(\mathrm{Ti}_{40} \mathrm{Zr}_{25} \mathrm{Cu}_{9} \mathrm{Ni}_{8} \mathrm{Be}_{18}\right)_{98} \mathrm{Y}_{2}$ crystal alloy, the compression rupture strength and plastic deformation are 1,819 $\mathrm{MPa}$ and only $0.1 \%$, respectively, indicating almost no plasticity. Besides, $\left(\mathrm{Ti}_{40} \mathrm{Zr}_{25} \mathrm{Cu}_{9} \mathrm{Ni}_{8} \mathrm{Be}_{18}\right)_{96} \mathrm{Nb}_{4}$ shows a breaking strength of 1,934 $\mathrm{MPa}$ and plastic strain of $8 \%$. These results show that the plastic strain of amorphous alloy has a strong dependence on the trace elements. No crystalline phase formed in the $\mathrm{Ti}_{40} \mathrm{Zr}_{25} \mathrm{Cu}_{9} \mathrm{Ni}_{8} \mathrm{Be}_{18}$ alloy with $\mathrm{Nb}$ addition, and thus, the increase in plasticity could not be attributed to the second phase. Unlike crystalline alloys, amorphous alloys have no defects such as dislocations and grain boundaries. The inherent instability of plastic deformation of amorphous alloys is related to the shear bands formed by the highly localized shear deformation occurring during the plastic deformation. Shear bands are closely related to the first pop-in in the plastic deformation in the nanoindentation test. To clarify the relationship between plastic strain and element addition during compression of amorphous alloys, the first pop-in event of amorphous alloys was studied by the nanoindentation test. Combined with the macroscopic compression characteristics, the plastic deformation mechanism of the amorphous alloy was studied. 
Table 1: Compressive properties parameters of seven samples

$\begin{array}{cccc}\text { Alloy } & \begin{array}{c}\text { Compressive strength } \\ (\mathrm{MPa})\end{array} & \begin{array}{c}\text { Max. plastic strain } \\ (\%)\end{array} & \begin{array}{c}\text { Max. total strain } \\ (\%)\end{array} \\ \mathrm{Ti}_{40} \mathrm{Zr}_{25} \mathrm{Cu}_{9} \mathrm{Ni}_{8} \mathrm{Be}_{18} & 1,896 & 2.1 & 5.1 \\ \left(\mathrm{Ti}_{40} \mathrm{Zr}_{25} \mathrm{Cu}_{9} \mathrm{Ni}_{8} \mathrm{Be}_{18}\right)_{99} \mathrm{Nb}_{1} & 1,842 & 2.3 & 5.3 \\ \left(\mathrm{Ti}_{40} \mathrm{Zr}_{25} \mathrm{Cu}_{9} \mathrm{Ni}_{8} \mathrm{Be}_{18}\right)_{98} \mathrm{Nb}_{2} & 1,901 & 2.9 & 6.0 \\ \left(\mathrm{Ti}_{40} \mathrm{Zr}_{25} \mathrm{Cu}_{9} \mathrm{Ni}_{8} \mathrm{Be}_{18}\right)_{97} \mathrm{Nb}_{3} & 2,177 & 13.0 & 15.9 \\ \left(\mathrm{Ti}_{40} \mathrm{Zr}_{25} \mathrm{Cu}_{9} \mathrm{Ni}_{8} \mathrm{Be}_{18}\right)_{96} \mathrm{Nb}_{4} & 1,934 & 8.0 & 11.0 \\ \left(\mathrm{Ti}_{40} \mathrm{Zr}_{25} \mathrm{Cu}_{9} \mathrm{Ni}_{8} \mathrm{Be}_{18}\right)_{99} \mathrm{Y}_{1} & 1,870 & 1.1 & 4.0 \\ \left(\mathrm{Ti}_{40} \mathrm{Zr}_{25} \mathrm{Cu}_{9} \mathrm{Ni}_{8} \mathrm{Be}_{18}\right)_{98} \mathrm{Y}_{2} & 1,819 & 0.1 & 3.3\end{array}$

\subsection{Fractured surface morphology of amorphous alloy}

The morphology of the fractured surface of the $\left(\mathrm{Ti}_{40} \mathrm{Zr}_{25} \mathrm{Cu}_{9} \mathrm{Ni}_{8} \mathrm{Be}_{18}\right)_{97} \mathrm{Nb}_{3}$ sample is shown in Fig. 4(a). It can be seen that a large number of shear bands are distributed in different directions of the sample. In the initial deformation stage, the main shear bands experience difficulty in spreading in the amorphous matrix. With the progress in deformation, a series of secondary shear bands, toward a direction different from that of the initial main shear bands, is generated to eliminate excessive deformation energy. When the secondary shear bands expand through the main shear bands, they are blocked by and interacted with the main shear bands, as shown in Fig. 4(b). The spacing of the secondary shear band is only 1-2 $\mu \mathrm{m}$, indicating intense plastic deformation of the amorphous sample. That is, the main shear bands effectively block the secondary shear bands. The shear strain in the deformation process is accommodated by the generation and stable extension of the plurality of shear bands; this ultimately leads to higher macroscopic compression ductility. The SEM images of the transversal and longitudinal section of the $\left(\mathrm{Ti}_{40} \mathrm{Zr}_{25} \mathrm{Cu}_{9} \mathrm{Ni}_{8} \mathrm{Be}_{18}\right)_{99} \mathrm{Y}_{1}$ alloy are shown in Figs. 4(c) and 4(d). A part of the shear bands are distributed on the lateral side of the sample, as indicated by the arrow in Fig. 3(c). The fracture surface shows three fracture morphologies: the droplet pattern (white ellipse), vein pattern (black ellipse), and shear bands (white arrow), indicating the generation of multiple shear bands [Figs. 4(a) and 4(b)].
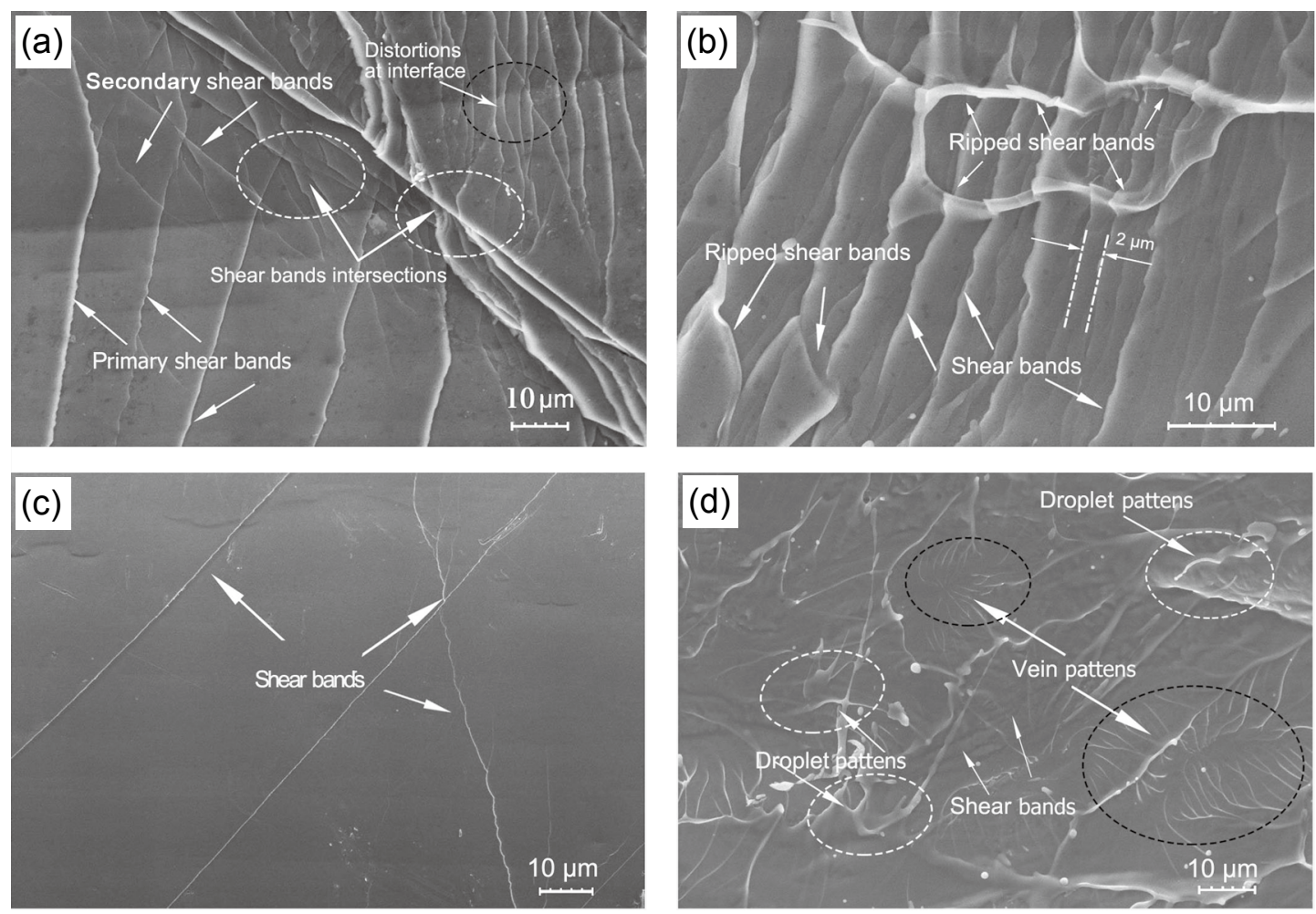

Fig. 4: Fractography of compressive fractured samples: (a), (b): $\left(\mathrm{Ti}_{40} \mathrm{Zr}_{25} \mathrm{Cu}_{9} \mathrm{Ni}_{8} \mathrm{Be}_{18}\right)_{97} \mathrm{Nb}_{3}$; (c), (d): $\left(\mathrm{Ti}_{40} \mathrm{Zr}_{25} \mathrm{Cu}_{9} \mathrm{Ni}_{8} \mathrm{Be}_{18}\right)_{99} \mathrm{Y}_{1}$; (a) and (c): side view; (b) and (d): top view 


\subsection{Plastic deformation energy of amorphous alloy}

Figure 5 shows the typical nanoindentation-based loaddisplacement ( $\mathrm{P}-\mathrm{h})$ curves of $\left(\mathrm{Ti}_{40} \mathrm{Zr}_{25} \mathrm{Cu}_{9} \mathrm{Ni}_{8} \mathrm{Be}_{18}\right)_{97} \mathrm{Nb}_{3}$ including loading and unloading. Based on the first point of the elastic theoretical curve given by Hertz theory ${ }^{[26]}$, the starting point of the plastic deformation occurring during loading can be determined through the experimental data. The plot is magnified to better illustrate the initial deviation from the elastic contact, as predicted using the Hertzian contact law and represented by the dashed line. The first pop-in event corresponds to a discontinuity.

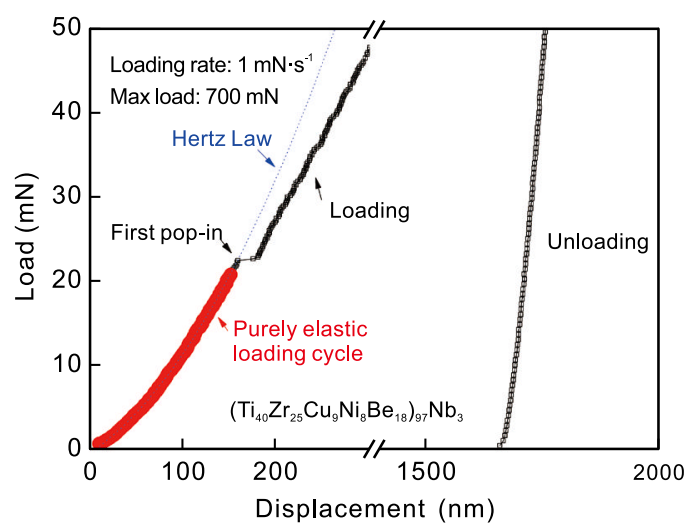

Fig. 5: Load-displacement (P-h) curve of $\left(\mathrm{Ti}_{40} \mathrm{Zr}_{25} \mathrm{Cu}_{9} \mathrm{Ni}_{8} \mathrm{Be}_{18}\right)_{97} \mathrm{Nb}_{3}$ bulk amorphous alloy at loading rate of $1 \mathrm{mN} \cdot \mathrm{s}^{-1}$

The $h_{\mathrm{t}}$ denotes indenter displacement at the beginning of the first pop-in, $h_{\mathrm{c}}$ is the corresponding contact depth of $h_{\mathrm{t}}$, given by ${ }^{[22,25,29-30] \text { : }}$

$$
h_{\mathrm{c}}=h_{\mathrm{t}}-\varepsilon \frac{F_{\max }}{S} \sqrt{\frac{F_{\mathrm{P}}}{F_{\text {max }}}}
$$

where $F_{\max }$ is the maximum load, the elastic unloading stiffness. $S=d P / d h$, defined as the slope of the upper portion of the unloading curve during the initial stages of unloading (also called the contact stiffness), and $\varepsilon$ is a constant that depends on the geometry of the indenter ( 0.75 for the spherical indenter), $F_{\mathrm{p}}$ is applied force of the first pop-in. $E_{\mathrm{r}}$ is the reduced modulus. $R$ is the indenter radius. Then, the average contact stress, $P_{\mathrm{m}}$, of the first pop-in can be calculated by ${ }^{[29-32]}$ :

$$
P_{\mathrm{m}}=\left(\frac{16 F_{\mathrm{p}} E_{\mathrm{r}}^{2}}{9 \pi^{3} R^{2}}\right)^{\frac{1}{3}}
$$

Figure 6 shows the load portion of typical nanoindentation P-h curves of $\mathrm{Ti}_{40} \mathrm{Zr}_{25} \mathrm{Cu}_{9} \mathrm{Ni}_{8} \mathrm{Be}_{18},\left(\mathrm{Ti}_{40} \mathrm{Zr}_{25} \mathrm{Cu}_{9} \mathrm{Ni}_{8} \mathrm{Be}_{18}\right)_{97} \mathrm{Nb}_{3}$, and $\left(\mathrm{Ti}_{40} \mathrm{Zr}_{25} \mathrm{Cu}_{9} \mathrm{Ni}_{8} \mathrm{Be}_{18}\right)_{99} \mathrm{Y}_{1}$. As shown in Fig. 6, load $F_{\mathrm{p}}$, indenter displacement $h_{\mathrm{t}}$, and displacement of first pop-in $(\Delta d)$ are significantly different in the three alloys. The sawtooth phenomenon can be clearly observed in the three P-h curves, indicating that the deformation process was interrupted by many pop-ins during the loading process. Figure 6 shows the enlarged images corresponding to the P-h curve at the first pop-in of (a), (b),

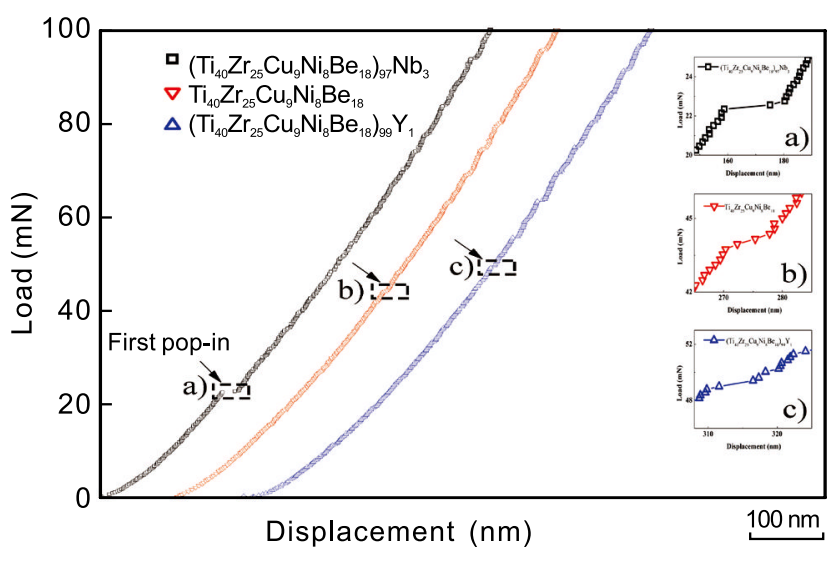

Fig. 6: Typical loading parts of the nanoindentation P-h curves of $\mathrm{Ti}_{40} \mathrm{Zr}_{25} \mathrm{Cu}_{9} \mathrm{Ni}_{8} \mathrm{Be}_{18},\left(\mathrm{Ti}_{40} \mathrm{Zr}_{25} \mathrm{Cu}_{9} \mathrm{Ni}_{8} \mathrm{Be}_{18}\right)_{99} \mathrm{Y}_{1}$, and $\left(\mathrm{Ti}_{40} \mathrm{Zr}_{25} \mathrm{Cu}_{9} \mathrm{Ni}_{8} \mathrm{Be}_{18}\right)_{97} \mathrm{Nb}_{3}$ samples at the loading rate of $1 \mathrm{mN} \cdot \mathrm{s}^{-1}$

and (c), respectively. On further enlarging the region of serration, it is found that a few points are recorded in the region of serration, implying the faster velocity of serration flow. In compression deformation, each serration corresponds to the nucleation of the shear bands and quickly leads to the plastic strain, causing a drop in load ${ }^{[33]}$. For the $\mathrm{Ti}_{40} \mathrm{Zr}_{25} \mathrm{Cu}_{9} \mathrm{Ni}_{8} \mathrm{Be}_{18}$ bulk amorphous alloy, the load, indenter displacement, and displacement at the first pop-in are $F_{\mathrm{p}}=44 \mathrm{mN}, h_{\mathrm{t}}=270 \mathrm{~nm}$, and $\Delta d=9.5 \mathrm{~nm} . F_{\mathrm{p}}$ is reduced to $22 \mathrm{mN}$ and $\Delta d$ increased to $22 \mathrm{~nm}$ with the addition of $\mathrm{Nb}$ element, indicating that the initial displacement of the first pop-in was easy. On the contrary, with the addition of the Y element to the bulk amorphous alloys, $F_{\mathrm{p}}$ increased to $49 \mathrm{mN}$ and $\Delta d$ remained almost unchanged, indicating that the addition of $\mathrm{Y}$ element requires a greater stress drive to cause the first pop-in. Table 2 shows the measured values of the load and displacement for the first displacement of the sample (average of 10 measurements).

The plastic strain $\left(W_{\mathrm{p}}\right)$ applied to operate these shear bands can be approximately estimated as ${ }^{[28]}$ :

$$
W_{\mathrm{p}}=F_{\mathrm{p}} \Delta d
$$

Further, the volume of the plastic deformation zone $\left(V_{\mathrm{p}}\right)$ can be estimated as ${ }^{[26]}$.

$$
\begin{aligned}
V_{\mathrm{p}}= & V_{\left(h_{\mathrm{c}}+\Delta d\right)}-V_{h_{\mathrm{c}}}=\frac{\pi\left(h_{\mathrm{c}}+\Delta d\right)}{6}\left[3 R^{2}+\left(h_{\mathrm{c}}+\Delta d\right)\right] \\
& -\frac{\pi h_{\mathrm{c}}}{6}\left(3 R^{2}+{h_{\mathrm{c}}}^{2}\right)
\end{aligned}
$$

where $V_{h_{\mathrm{c}}}$ is volume of the plastic deformation zone. $V_{\left(h_{\mathrm{c}}+\Delta d\right)}$ is the total deformation zone.

The PDE $(U)$ of the first pop-in can be calculated as ${ }^{[28]}$ :

$$
U=\frac{W_{\mathrm{p}}}{V_{\mathrm{p}}}
$$

where $W_{\mathrm{p}}$ is plastic strain applied to operate the first pop-in; $V_{\mathrm{p}}$ the shear deformation volume during the first pop-in.

The measured PDE results of the three amorphous alloy samples are shown in Table 3. 
Table 2: Measured indenter displacement $\left(h_{\mathrm{t}}\right)$, contact depth of $h_{\mathrm{t}}\left(h_{\mathrm{c}}\right)$, sudden displacement of indenter $(\Delta d)$, applied force $\left(F_{\mathrm{p}}\right)$, contact pressure $\left(P_{\mathrm{m}}\right)$, and critical shear stress $\left(\boldsymbol{T}_{\text {crit }}\right)$ at occurrence of the first pop-in for three samples

$\begin{array}{ccccccc}\text { Alloy } & \boldsymbol{h}_{\mathrm{t}}(\mathrm{nm}) & \boldsymbol{h}_{\mathrm{c}}(\mathrm{nm}) & \boldsymbol{F}_{\mathrm{p}}(\mathrm{mN}) & \boldsymbol{\Delta d}(\mathrm{nm}) & \boldsymbol{P}_{\mathrm{m}}(\mathrm{GPa}) & \boldsymbol{T}_{\text {crit }}(\mathrm{GPa}) \\ \mathrm{Ti}_{40} \mathrm{Zr}_{25} \mathrm{Cu}_{9} \mathrm{Ni}_{8} \mathrm{Be}_{18} & 270.41 & 153.93 & 43.73 & 7.56 & 6.54 & 2.91 \\ \left(\mathrm{Ti}_{40} \mathrm{Zr}_{25} \mathrm{Cu}_{9} \mathrm{Ni}_{8} \mathrm{Be}_{18}\right)_{97} \mathrm{Nb}_{3} & 146.43 & 69.88 & 19.34 & 17.12 & 4.98 & 2.22 \\ \left(\mathrm{Ti}_{40} \mathrm{Zr}_{25} \mathrm{Cu}_{9} \mathrm{Ni}_{8} \mathrm{Be}_{18}\right)_{99} \mathrm{Y}_{1} & 340.72 & 210.52 & 55.48 & 6.36 & 7.08 & 3.10\end{array}$

Table 3: Calculated plastic deformation energy of the three samples

$\begin{array}{ccccc}\text { Alloy } & W_{\mathrm{p}}(\mathrm{J}) & \boldsymbol{V}_{\mathrm{p}}\left(\mathrm{m}^{3}\right) & \boldsymbol{U}\left(\boldsymbol{W}_{\mathrm{p}} / \boldsymbol{V}_{\mathrm{p}}\right)\left(\mathrm{J} \cdot \mathrm{m}^{-3}\right) & \text { Max. plastic strain }(\%) \\ \mathrm{Ti}_{40} \mathrm{Zr}_{25} \mathrm{Cu}_{9} \mathrm{Ni}_{8} \mathrm{Be}_{18} & 3.31 \times 10^{-10} & 1.38 \times 10^{-18} & 2.39 \times 10^{8} & 2.1 \\ \left(\mathrm{Ti}_{40} \mathrm{Zr}_{25} \mathrm{Cu}_{9} \mathrm{Ni}_{8} \mathrm{Be}_{18}\right)_{97} \mathrm{Nb}_{3} & 3.29 \times 10^{-10} & 3.13 \times 10^{-18} & 1.05 \times 10^{8} & 13.0 \\ \left(\mathrm{Ti}_{40} \mathrm{Zr}_{25} \mathrm{Cu}_{9} \mathrm{Ni}_{8} \mathrm{Be}_{18}\right)_{99} \mathrm{Y}_{1} & 3.53 \times 10^{-10} & 1.17 \times 10^{-18} & 3.03 \times 10^{8} & 1.1\end{array}$

\section{Discussion}

Table 3 shows that the PDE value is clearly reduced by $57 \%$ and increased by $30 \%$ after the addition of $\mathrm{Nb}$ and $\mathrm{Y}$, respectively. Wang et al. ${ }^{[26]}$ pointed out that the PDE value of bulk amorphous alloys is intrinsically related to the formation ability of shear bands and directly related to the plastic deformation ability of bulk amorphous alloys. This portion of atoms with the surrounding atoms are called the shear transition zone (STZ) ${ }^{[34,35]}$. Figure 7 shows the plastic deformation model of the amorphous alloy at its first pop-in. The filled and open circles represent atoms with low and high propensity of motion, respectively. The arrows indicate the possible motion of atoms. The potential shear transition zone events are localized in a cooperative manner and are reversible owing to confinement of surrounding materials, while the plastic flow incorporates large-scale atomic migration and is irreversible. Some atoms cause larger displacements than the surrounding atoms because of shear deformation. Figure 7(a) shows the potential energy variation curve of $\mathrm{Ti}_{40} \mathrm{Zr}_{25} \mathrm{Cu}_{9} \mathrm{Ni}_{8} \mathrm{Be}_{18}$. As is known, during the plastic deformation of amorphous alloys, the shear transition zone first nucleates at the lowest energy threshold and the further development of shear transition zone nucleation forms a shear band. The addition of $\mathrm{Nb}$ decreases the PDE of amorphous alloys, resulting in the decrease of the potential energy barrier of atomic-migrationforming plastic flow, as shown in Fig. 7(b). The addition of $Y$ increases the PDE of amorphous alloys, indicating an increase in the potential energy barrier of atomic-migration-forming plastic flow, as shown in Fig. 7(c). This is verified by the PDE values of the three amorphous alloys.

In summary, the shear bands will nucleate in these shear transition zones when the stress or deformation energy exceeds the threshold during plastic deformation. The $\left(\mathrm{Ti}_{40} \mathrm{Zr}_{25} \mathrm{Cu}_{9} \mathrm{Ni}_{8} \mathrm{Be}_{18}\right)_{97} \mathrm{Nb}_{3}$ amorphous alloy has a lower $\mathrm{PDE}$, and its shear bands may easily generate, proliferate, and expand under a low energy barrier, resulting in uniform

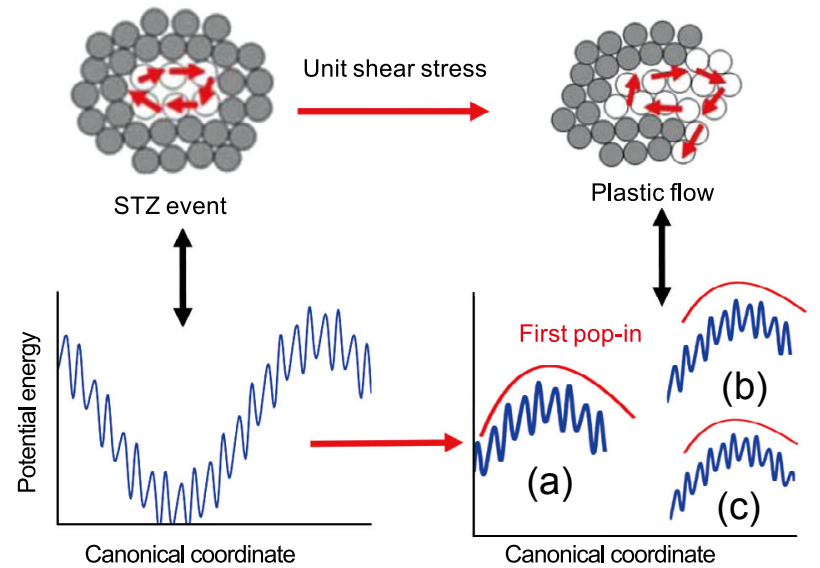

Fig. 7: Plastic deformation model of amorphous alloy at the first pop-in: (a) $\mathrm{Ti}_{40} \mathrm{Zr}_{25} \mathrm{Cu}_{9} \mathrm{Ni}_{8} \mathrm{Be}_{18}$; (b) $\left(\mathrm{Ti}_{40} \mathrm{Zr}_{25} \mathrm{Cu}_{9} \mathrm{Ni}_{8} \mathrm{Be}_{18}\right)_{97} \mathrm{Nb}_{3}$; (c) $\left(\mathrm{Ti}_{40} \mathrm{Zr}_{25} \mathrm{Cu}_{9} \mathrm{Ni}_{8} \mathrm{Be}_{18}\right)_{99} \mathrm{Y}_{1}$

plasticity. Pan et al ${ }^{[24]}$ showed that the size of the shear transition zone is fundamentally related to the plasticity of amorphous alloys. When the amorphous alloy has a low PDE, its shear transition zone is large, and the shear bands are easily produced (low energy threshold), showing a certain plastic deformation ability. It is well known that the crosssectional morphology is related to the mechanical properties of the material. In addition, the section morphology rich in shear bands is related to ductile fracture, while the section morphology of cleavage fracture is a brittle fracture, depending on the value of the PDE. The existence of more droplet patterns is based on a high elastic energy in the deformation process. When the sample breaks, the heat released in a relatively narrow space and short time causes remelting of a part of the amorphous matrix ${ }^{[36]}$. A few vein patterns are formed during the gradual sliding expansion of the main shear bands owing to the obstruction (and absorption) of the shear bands by the amorphous matrix. In addition, the appearance of the shearing step on the fracture surface indicates that the amorphous matrix 
failed to effectively hinder the expansion of the shear bands and the subsequent cracking. Moreover, owing to the increase in the instantaneous temperature of the crack (adiabatic exotherm), microscale vein patterns are produced. As a fewer shear bands are generated, the plastic rheology is confined within the main shear bands. Therefore, with the addition of $\mathrm{Y}$ element, the $\left(\mathrm{Ti}_{40} \mathrm{Zr}_{25} \mathrm{Cu}_{9} \mathrm{Ni}_{8} \mathrm{Be}_{18}\right)_{99} \mathrm{Y}_{1}$ amorphous alloy shows a lower plasticity than that of the $\left(\mathrm{Ti}_{40} \mathrm{Zr}_{25} \mathrm{Cu}_{9} \mathrm{Ni}_{8} \mathrm{Be}_{18}\right)_{97} \mathrm{Nb}_{3}$ alloy.

The plasticity in the crystalline material is related to dislocation defects, while the plastic deformation of the amorphous alloy is confined to the narrow shear bands with the gathering of too many disordered atoms. Bulk amorphous alloys are compressed to high stress at room temperature and the plastic strain is confined within the nano-sized shearbands region, causing catastrophic fracture based on a nonuniform strain. Further, the atoms are rearranged in a short range during the deformation process, and free volume is accumulated in excess ${ }^{[37]}$, resulting in the formation of free volume accumulation zones. In the process of deformation, the shear transition zone is easily generated in the free volume accumulation zones with a very small energy barrier and the nucleation zone of the shear bands ${ }^{[38]}$. The achievement of the required shear stress value during the deformation process of the relatively loosely dispersed atomic group is easy, and the adjacent atoms are rearranged to reach this value to form shear transition zones. The generation and development of shear transition zones is strongly influenced by the local atomic arrangement, in which the relatively loose position of the deposited atoms is susceptible to shear strain under the shear stress. The shear bands propagation is triggered by the meeting of the shear bands; this increases the fluidity of the plastic deformation of the bulk amorphous alloy and produces an overall ductility with a large plastic strain. According to research $^{[9-11]}$, the complete suppression of a shear band or inhibition of multiple shear bands is effective for the room temperature plasticity of bulk amorphous alloy. However, the length scale required to suppress the shear band is less than 20 $\mathrm{nm}$. Although the shear band can transfer between phases with slight energy loss, thus promoting the controllable proliferation and diffusion of shear band, the composite properties of microstructure will hinder the diffusion of shear band, thus leading to plastic enhancement. Furthermore, the displacement of a pop-in during nanoindentation actually corresponds to the formation of shear bands by the nanoindentation test ${ }^{[39]}$. The results obtained by Schuh ${ }^{[40]}$ and Packard ${ }^{[41]}$ revealed the formation of shear bands (or first pop-in) controlled by high stress along a feasible shear plane in the nanoindentation test of spherical indenter. Shear bands are formed when the stress reaches a critical threshold, rather than being controlled by the highest stress near the principal stress. The ability of plastic deformation of amorphous alloys depends on the nucleation and propagation of shear bands during the deformation. In the nanoindentation experiment, a pop-in in the load-displacement curve indicates material strain as well as the generation and expansion of the shear bands. Thus, shear bands can only be produced under high energy barriers with only a few shear bands nucleating, generating, and expanding, exhibiting minimal plasticity and subsequent fracture.

\section{Conclusion}

A series of $\left(\mathrm{Ti}_{40} \mathrm{Zr}_{25} \mathrm{Cu}_{9} \mathrm{Ni}_{8} \mathrm{Be}_{18}\right)_{100-x} \mathrm{TM}_{x}(x=0,1,2,3,4$ at.\%, $\mathrm{TM}=\mathrm{Nb}, \mathrm{Y}$ ) alloys were prepared using the copper mold casting process with vacuum melting. The effects of $\mathrm{Nb}$ or $\mathrm{Y}$ addition on macro and micro mechanical properties of $\mathrm{Ti}_{40} \mathrm{Zr}_{25} \mathrm{Cu}_{9} \mathrm{Ni}_{8} \mathrm{Be}_{18}$ bulk amorphous alloys were investigated.

It was found that the addition of $Y$ element reduces the fracture strength and plastic strain of the alloy, and the addition of $\mathrm{Nb}$ element increases the fracture strength and plastic strain by the macro-compression test. The fracture strength and plastic strain of $\left(\mathrm{Ti}_{40} \mathrm{Zr}_{25} \mathrm{Cu}_{9} \mathrm{Ni}_{8} \mathrm{Be}_{18}\right)_{97} \mathrm{Nb}_{3}$ amorphous alloy are the maximum among the seven samples. The plastic deformation energy of $\left(\mathrm{Ti}_{40} \mathrm{Zr}_{25} \mathrm{Cu}_{9} \mathrm{Ni}_{8} \mathrm{Be}_{18}\right)_{99} \mathrm{Y}_{1}$ amorphous alloy is $30 \%$ higher than $\mathrm{Ti}_{40} \mathrm{Zr}_{25} \mathrm{Cu}_{9} \mathrm{Ni}_{8} \mathrm{Be}_{18}$, and the plastic deformation energy of $\left(\mathrm{Ti}_{40} \mathrm{Zr}_{25} \mathrm{Cu}_{9} \mathrm{Ni}_{8} \mathrm{Be}_{18}\right)_{97} \mathrm{Nb}_{3}$ amorphous alloy is $57 \%$ lower than $\mathrm{Ti}_{40} \mathrm{Zr}_{25} \mathrm{Cu}_{9} \mathrm{Ni}_{8} \mathrm{Be}_{18}$. The alloy with $\mathrm{Nb}$ addition can cause the nucleation of the shear band, making the shear band easily generated in the high energy state. However, the effect of $\mathrm{Y}$ addition is opposite to that of $\mathrm{Nb}$. $\left(\mathrm{Ti}_{40} \mathrm{Zr}_{25} \mathrm{Cu}_{9} \mathrm{Ni}_{8} \mathrm{Be}_{18}\right)_{99} \mathrm{Y}_{1}$ amorphous alloy presents a high plastic deformation energy, fewer shear bands, thus reducing the ultimate strength and plastic strain.

\section{Acknowledgements}

This work was supported by the National Natural Science Foundation of China (Grant Nos.: 51434008, 51671166, 51471143).

\section{References}

[1] Inoue A, Takeuchi A. Recent development and application products of bulk glassy alloys. Acta Materialia, 2011, 59(6): 2243-2267.

[2] Yang W M, Sun B A, Zhao Y C, et al. Non-repeatability of large plasticity for Fe-based bulk metallic glasses. Journal of Alloys and Compounds, 2016, 676: 209-214.

[3] Gao X F, Ge N, Dong F Y, et al. Deformation and fracture of a $\mathrm{Zr}$-Al-Cu metallic glass ribbon under tension near glass transition temperature. China Foundry, 2018, 15(3): 216-221.

[4] Schuh C A, Hufnagel T C, Ramamurty U, et al. Mechanical behavior of amorphous alloys. Acta Materialia, 2007, 55(12): 4067-4109.

[5] Pont M, Rao K V, Inoue A, et al. Magnetic properties of Co-B-C amorphous alloys melt-quenched beyond the eutectic regime. Journal of Applied Physics, 1988, 63(8): 3397.

[6] Xiang Q C, Feng Z B, Zhang W, et al. Effect of infiltrating time on interfacial reaction and properties of tungsten particles reinforced $\mathrm{Zr}$-based bulk metallic glass composites. China Foundry, 2020, 17(4): 253-259.

[7] Bratislav C, Nebojsa M, Aleksa M. Effect of heat treatment on structure and magnetic properties of $\mathrm{Fe}(65.5) \mathrm{Cr} 4 \mathrm{Mo} 4 \mathrm{Ga} 4 \mathrm{P}(12)$ C5B(5.5) bulk amorphous alloy. China Foundry, 2017, 14(1): 59-63. 
[8] Zhang Q S, Qin C L, Inoue A. Cast bulk glassy alloys: fabrication, alloy development and properties. China Foundry, 2010, 7(3): 278-286.

[9] Argon A S. Plastic deformation in metallic glasses. Acta Metallurgica, 1979, 27(1): 47-58.

[10] Wang W H. Correlations between elastic moduli and properties in bulk metallic glasses. Journal of Applied Physics, 2006, 99(9): 1947-135.

[11] Wang W H, Bian Z, Wen P. Role of addition in formation and properties of $\mathrm{Zr}$-based bulk metallic glasses. Intermetallics, 2002, 10(11-12): 1249-1257.

[12] Chen N, Laura m, Luzguine-Luzgin D V, et al. Role of alloying additions in glass formation and properties of bulk metallic glasses. Materials, 2010, 3(12): 5320-5339.

[13] Inoue A. Bulk amorphous and nanocrystalline alloys with high functional properties. Materials Science and Engineering: A 2001, s304-306: 1-10.

[14] Chai A H, Ding D W, Liu Y, et al. A series of Zr-based bulk metallic glasses with room temperature plasticity. Materials, 2016, 9(6): 408.

[15] Liu R S, Li J Y. On the structural defects and microscopic mechanism of the high strength of amorphous alloys. Materials Science and Engineering A, 1989, 114: 127-132.

[16] Han Z H, Feng Y Y, Li F. Microstructure evolution and shear band propagation induced by the addition of trace $\mathrm{Nb}$ in $\mathrm{Cu}$ $\mathrm{Zr}$-Ti based amorphous alloy. Thermal Processing Technology, 2019, 48(8): 84-87. (In Chinese)

[17] Wu X W, Zhou Y, Chen F, et al. Effect of $\mathrm{Nb}$ addition on corrosion and mechanical properties of Ti-based amorphous alloy. Materials Science and Technology, 2019, 27(1): 73-80. (In Chinese)

[18] Du X H, Huang J C, Hsieh K C, et al. Two-glassy-phase bulk metallic glass with remarkable plasticity. Applied Physics Letters, 2007, 91(13): 45.

[19] Conner R D, Li Y, Nix W D, et al. Shear band spacing under bending of Zr-based metallic glass plates. Acta Materialia, 2004, 52(8): 2429-2434.

[20] Fu K K, Chang L, Ye L, et al. Thickness-dependent fracture behaviour of amorphous carbon films on a PEEK substrate under nanoindentation. Vacuum, 2017, 144: 107-115.

[21] Pi H, Wang Z Z, He X C, et al. Research on nanoindentation of hardness and elastic modulus of copper-based bulk amorphous alloy. Rare Metal Materials and Engineering, 2018, 47(2): 479-484. (In Chinese)

[22] Fischer-Cripps, Craig A. The measurement of hardness of very hard materials. Surface \& Coatings Technology, 2016, 29: 314-317.

[23] Yan X Q, Huang X M, Uda S, et al. Effect of heavy boron doping on pressure-induced phase transitions in single-crystal silicon. Applied Physics Letters, 2005, 87(19): 762.

[24] Pan D, Nieh T G, Chen M W. Strengthening and softening of nanocrystalline nickel during multistep nanoindentation. Applied Physics Letters, 2006, 88(16): 593.
[25 Bei H, Lu Z P, George E P. Theoretical strength and the onset of plasticity in bulk metallic glasses investigated by nanoindentation with a spherical indenter. Physical Review Letters, 2004, 93: 125504.

[26] Wang K, Pan D, Chen M W, et al. Measuring elastic energy density of bulk metallic glasses by nanoindentation. Materials Transactions, 2006, 47(8): 1981-1984.

[27] Schuh C A, Nieh T G. A survey of instrumented indentation studies on metallic glasses. Journal of Materials Research, 2004, 19(1): 46-57.

[28] Wang K, Chen M W, Pan D, et al. Plastic deformation energy of bulk metallic glasses. Materials Science \& Engineering B, 2008, 148(1-3): 101-104.

[29] Johnson K L. Contact mechanics. Cambridge University Press, Cambridge, 1985.

[30] Hay J L, Pharr G M, Kuhn H. ASM Handbook, Volume 8, Mechanical Testing and Evaluation, ASM, Materials Park, 2000.

[31] Oliver W C, Pharr G M. Measurement of hardness and elastic modulus by instrumented indentation. Journal of Materials Research, 2004. doi:10.1557/jmr.2004.19.1.3.

[32] Pharr G M, Oliver W C, Brotzen F R. On the generality of the relationship among contact stiffness, contact area, and elastic modulus during indentation. Journal of Materials Research, 1992, 7(3): 613-617.

[33] Qiao J W, Zhang Y, Liaw P K. Serrated flow kinetics in a Zrbased bulk metallic glass. Intermetallics, 2010, 18(11): $2057-$ 2064.

[34] Huang H, Yan J W. Investigating shear band interaction in metallic glasses by adjacent nanoindentation. Materials Science and Engineering: A, 2017, 704: 375-385.

[35] Wang L, Wang L, Xue Y F, et al. Nanoindentation response of laser shock peened Ti-based bulk metallic glass. AIP Advances, 2015, 5(5): 1947.

[36] Lewandowski J J, Greer A L. Temperature rise at shear bands in metallic glasses. Nature Materials, 2006, 5(1): 15-18.

[37] Stolpe M, Kruzic J J, Busch R. Evolution of shear bands, free volume and hardness during cold rolling of a Zr-based bulk metallic glass. Acta Materialia, 2014, 64: 231-240.

[38] Zhao L, Ma C L, Fu M W, et al. Investigation on the structural characteristics of metallic glasses based on the first displacement excursion behavior in nanoindentation. Materials Science and Engineering: A, 2011, 530: 196-201.

[39] Pi J H, Wang Z Z, He X C, et al. Nanoindentation mechanical properties of a Bi-phase $\mathrm{Cu}_{29} \mathrm{Zr}_{32} \mathrm{Ti}_{15} \mathrm{Al}_{5} \mathrm{Ni}_{19}$ alloy. Journal of Materials Engineering \& Performance, 2016, 25(1): 76-82.

[40] Schuh C A, Nieh T G. A nanoindentation study of serrated flow in bulk metallic glasses. Acta Materialia, 2003, 51(1): 87-99.

[41] Packard C E, Schuh C A. Initiation of shear bands near a stress concentration in metallic glass. Acta Materialia, 2007, 55: 5348-5358. 